\title{
Meta-análisis: Inhibidores de la enzima convertidora de angiotensina y progresión de nefropatía no diabética
}

Effect of Angiotensin-Converting Enzime inhibitors on the progression of nondiabetic renal disease: A Meta- Analysis of Randomized Trials. Giatras I, Lau J, Levey A, for the Angiotensin- Converting-Enzyme Inhibition and Progressive renal Disease Study Group. Ann Intern Med. 1997; 127:337-345

\section{Objetivo}

Revisar y determinar comparativamente el efecto sobre la progresión de enfermedad renal no relacionada con la diabetes, de los inhibidores de la enzima convertidora de angiotensina (IECA) y otras drogas antihipertensivas.

\section{Fuente y selección de datos}

Los autores realizaron la búsqueda desde 1977 hasta Mayo de 1996 a través de MEDLINE limitándose a artículos en inglés. También revisaron referencias, revisiones y presentaciones hechas en congresos internacionales. Contactaron además a los principales investigadores en este tema, en referencia a lo publicado o sobre información no publicada. Como criterio de inclusión, se seleccionaron ensayos clínicos randomizados comparando inhibidores de la ECA versus otros antihipertensivos con un seguimiento de por lo menos 1 año. Se incluyeron un total de 1594 pacientes provenientes de 10 estudios (7 publicados y tres no publicados). Los datos seleccionados fueron: progresión a la enfermedad renal terminal, mortalidad, abandono del tratamiento y valores de tensión arterial.

\section{Resultados principales}

De los 806 pacientes que recibieron IECA, $52(6,4 \%)$ desarrollaron insuficiencia renal terminal y $17(2,1 \%)$ murieron. En los 788 que recibieron otras drogas, los valores respectivos fueron $72(9.1 \%)$ y $12(1,5 \%)$. El riesgo relativo agrupado fue 0,70 ( $95 \%$ IC 0,51 a 0.97$)$ para insuficiencia renal terminal y 1.24 ( $95 \%$ IC 0.55 a 2.83) para mortalidad ( $p$ No Significativa). Los pacientes que recibieron IECA tuvieron un mayor descenso de la tensión arterial $(4.9 \mathrm{mmHg}$ en la sistólica y $1.2 \mathrm{mmHg}$ en la diastólica)

\section{Conclusión}

Los IECA en general son más efectivos que otros antihipertensivos en disminuir la velocidad de progresión de la enfermedad renal hacia la insuficiencia crónica en pacientes no diabéticos. No existen diferencias en cuanto a la mortalidad. Debido al mayor descenso de la tensión arterial con IECA no se puede aún determinar si este efecto es debido a una disminución de la presión arterial o a un efecto intrínseco de este grupo farmacológico.

Fuente de financiamiento: Oficina gubernamental para la investigación y políticas de salud (AHCPR) y los laboratorios MSD, Roche y Bayer que sustentaron los estudios originales.

\section{COMENTARIO}

Debido a la clara evidencia sobre la acción beneficiosa de los IECA sobre la velocidad de progresión de la nefropatía diabética $(1,2)$, se han desarrollado numerosos estudios en los últimos años buscando extender esta acción a otras causas de insuficiencia renal. Los resultados previos fueron disímiles, por lo que se hizo necesario un metanálisis para evaluar la evidencia disponible a la fecha (esta es una de las funciones más útiles de este tipo de estudios). Los autores concluyen que existe un beneficio estadístico y clínicamente significativo según los eventos por ellos elegidos. Metodológicamente el estudio es muy bueno por el grado de detalle y exigencia demostrado en la selección de trabajos y en la búsqueda de datos no publicados. Es importante que solo hayan seleccionado ensayos clínicos randomizados, porque proveen datos con el mejor nivel de evidencia. Un problema importante en la interpretación de los resultados es considerar la heterogeneidad de patologías incluidas en estos estudios y su duración (1 a 4 años). Hay que señalar que como la nefropatía no diabética es una complicación poco frecuente de la hipertensión el nivel de protección que demostraron los IECA tuvo un rango importante de variación ya que la reducción relativa de nefropatía osciló entre el 3\% y el $49 \%$. Además solo se evalúo mortalidad pero no se puede estable- cer el grado de morbilidad comparativa que producen estas drogas y los otros grupos evaluados. No se estudiaron diferencias entre los distintos tipos de inhibidores de la ECA, siendo el enalapril el más utilizado. Debido a que no se pudo determinar si la disminución de la presión arterial fue el principal factor que logró la desaceleración de la progresión, sería interesante en el futuro establecer si otro grupo de drogas logran este efecto a igual descenso de la tensión arterial. Esto, junto a lo previamente descripto, es vital para la toma de decisión sobre si estas drogas deben ser utilizadas en forma selectiva en la hipertensión; conclusión que no puede establecerse en forma definitiva a partir de este estudio. Teniendo en cuenta que existen otras alternativas igualmente eficaces y más baratas en el manejo de la hipertensión arterial, este dato sería de suma relevancia para decidir cambiar conducta.

\section{Dr. Ezequiel García Elorrio}

Clínica Médica C.E.M.I.C.

\section{Referencias}

1. Viberti G, Mogensen CE, Groop LC y cols. Effect of captopril on progression to clinical proteinuria in patients with insulin-dependent diabetes mellitus and microalbuminuria. European microalbuminuria captopril study group. JAMA 1994;271:275-9

2. Kasiske BL, Kalil RS, Ma JZ y cols. Effect of antihypertensive therapy on the kidney in patients with diabetes: a meta-regression analysis. Ann Intern Med 1993;118:129-38. 